\title{
A adoção e o processo adotivo em Portugal*
}

\section{Adoption and the adoption process in Portugal}

\author{
Ana Susana Almeida, Universidade do Algarve, Portugal (asalmeida@ualg.pt) \\ Cristina Nunes, Centro de Investigação em Psicologia - CIP/UAL, Portugal (csnunes@ualg.pt) \\ Marina Fuertes, Instituto Politécnico de Lisboa, Portugal (marinaf@eselx.ipl.pt) \\ Jean-Christophe Giger, Centro de Investigação em Psicologia - CIP/UAL, Portugal (jhgiger@ualg.pt) \\ Sandra Mendonça, Associação António Aleixo, Portugal (svm.mendonca@gmail.com) \\ Lília Silva, Agrupamento de Escolas de Grândola, Portugal (liliacpsilva@gmail.com)
}

Resumo: Um vasto conjunto de especificidades formais relativas ao processo adotivo e às vivências das famílias por adoção é considerado como do domínio dos peritos da adoção. Contudo, a informação relativa ao processo adotivo nos últimos anos começou a ser socialmente divulgada e acessível embora dispersa em parcos documentos formais e legais. O presente artigo tem como objetivos apresentar a conceptualização multidimensional da adoção bem como a experiência formal, social e pessoal do processo adotivo para a comunidade não perita, guiado pelas seguintes questões: Como é o percurso formal da adoção? Como deve decorrer o processo adotivo? Como é vivido pelos futuros pais adotivos? Que aspetos estão envolvidos e são relevantes conhecer? Com este artigo pretende-se contribuir para a reflexão sobre o percurso das famílias por adoção em Portugal.

Palavras-Chave: adoção, pais adotivos, Portugal, processo adotivo

\begin{abstract}
There is a wide range of formal specificities related to the adoption process and the experiences of adoptive families that are considered to be within the domain of adoption experts. Only in recent years the information about the adoption process has started to be socially disseminated and accessible although dispersed in sparse formal and legal documents. The aims of this paper were to describe the multidimensional conceptualization of adoption and the formal, social and personal experience of the adoption process for the non-expert community. How is the formal adoption process? How should the adoption process take place? How is it experienced by prospective adoptive parents? What aspects are involved? With this paper we intend to contribute to answer these questions and to describe the pathway of families through adoption in Portugal.
\end{abstract}

Keywords: adoption, adoption process, adoptive parents, Portugal 
A adoção integra a história da humanidade. Investigações antropológicas evidenciam a transversalidade temporal e a transculturalidade da prática da adoção (Weckler, 1953). A adoção faz parte de diferentes sociedades desde épocas longínquas (Mascarenhas \& Alarcão, 2002). No decurso da sua existência a adoção tem sido pautada por diferentes perspetivas, atitudes e procedimentos concordantes com os cenários históricos, sociais e políticos caracterizadores de cada época e sociedade (Goiri \& Latorre, 2010; Mascarenhas \& Alarcão, 2002). Considerando o momento sócio histórico e político atual como se define a adoção? Como é o processo formal, social e familiar subjacente ao construir-se família por adoção? De que forma os pais e os filhos experienciam as suas primeiras vivências como famílias adotivas?

\section{Definição de adoção}

A adoção é um processo gradativo, que possibilita a um casal ou a uma pessoa conceber um "vínculo de filiação" com uma criança ou jovem (Instituto da Segurança Social - ISS, I.P., 2019, p. 4). Constitui uma resposta social dirigida a crianças desprovidas de cuidados familiares adequados, que tem como principal finalidade "realizar o superior interesse da criança" (Lei no 31/2003, p. 5313), devendo revestir-se de benefícios efetivos para a criança ou jovem a adotar (ISS - I.P., 2019).

Atualmente, a adoção pode ser nacional ou internacional. A adoção nacional em Portugal implica que o candidato à adoção e a criança a adotar, independentemente das suas nacionalidades, tenham residência habitual em Portugal (Lei 143/2015, p. 7235). A adoção internacional acarreta, no âmbito do processo adotivo, a transferência da criança a adotar do país onde habitualmente reside para um país diferente onde os futuros pais adotivos residem (ISS, I.P., 2019; Lei 143/2015, p. 7235). Os candidatos à adoção podem apresentar simultaneamente duas candidaturas, uma nacional e outra internacional (ISS, I.P., 2019). Podem ser ainda considerados dois tipos distintos de adoção, a plena e a restrita. $\mathrm{Na}$ adoção plena, são eliminadas as relações familiares do adotado com a família biológica, perdendo os apelidos de origem, tornando-se filho do(s) adotante (s), integrando a sua família e adquirindo os apelidos da família adotiva (ISS, I.P., 2014). A adoção plena é irrevogável em qualquer circunstância e os direitos sucessórios dos adotados são análogos aos dos descendentes naturais. Na adoção restrita, não existe 0 mesmo carácter definitivo da adoção plena, sendo preservados os direitos e deveres relativos à família biológica. Por solicitação do adotante, o adotado pode adquirir os apelidos do(s) adotante(s), sendo estes adicionados ao(s) apelido(s) da família biológica. Neste tipo de adoção não existe o direito de herança entre os adotados, os seus descendentes e os parentes do adotante, tal como não se encontram mutuamente obrigados à prestação de alimentos. A adoção restrita por solicitação dos adotantes, e uma vez cumpridos os critérios legalmente estipulados, pode a qualquer momento ser convertida, por decisão judicial, numa adoção plena (ISS, I.P., 2014).

Tendo em consideração os objetivos e as características subjacentes à adoção em Portugal, atualmente é perspetivada como uma decisão formal e jurídica, um processo decisivo, complexo e temporalmente alargado que envolve diretamente uma díade adotiva (i.e., os adotados e os pais adotivos). No seu cerne, a adoção consiste em proporcionar uma família, cujas características sugerem a capacidade para amar, garantir a saúde e segurança, bem como educação e o seu potencial desenvolvimental, a uma criança ou jovem que se encontra, por motivos diversificados, destituída(o) de um sistema familiar adequado ao seu bem-estar global e à sua qualidade de vida.

\section{O processo formal da adoção em Portugal: Da candidatura à integração da criança}

Atualmente, em Portugal, os candidatos a futuros pais adotivos têm de "embarcar" num vasto e rigoroso processo, de natureza administrativa e judicial, de avaliação, preparação e seleção realizado pela entidade responsável pelos processos adotivos (ISS, I.P., 2019; Lei 143/2015). Para ser possível a formação de famílias adequadas e sólidas, torna-se imprescindível a existência de um rigoroso processo de rastreio, avaliação, seleção e acompanhamento destas famílias, por parte de técnicos sérios e sa- 
pientes (Ribeiro \& Teixeira, 2012). Pretende-se que os profissionais envolvidos no processo de adoção sejam capazes de contribuir para a construção de projetos de adoção que sejam realistas e de instigar crescimento nas famílias, de forma a que se caraterizem como detentoras de sensibilidade, conhecimentos e competências capazes de antecipar e resolver as dificuldades que enfrentam, com confiança no seu reportório de estratégias parentais (Ribeiro \& Teixeira, 2012).

\subsection{Etapa preliminar: o contacto inicial dos inte- ressados com as entidades responsáveis pelo pro- cesso de candidatura à adoção}

O processo formal da adoção e o percurso como candidato inicia-se com o primeiro contacto do(s) interessado(s) com a entidade de Segurança Social da área de residência, especificamente com a equipa de adoção (Direção Geral da Segurança Social - DGSS, 2004), podendo ser por via pessoal ou eletrónica revelando a intenção de adotar uma criança ou jovem (DGSS, 2004; Lei 143/2015, ver Artigo 43º. De acordo com a área de residência os candidatos podem contactar diferentes entidades (i.e., a Santa Casa da Misericórdia de Lisboa, o Instituto da Segurança Social dos Açores, o Instituto da Segurança Social da Madeira e o Centro Distrital de Segurança Social - em qualquer outra zona do país) (ISS, I.P., 2014; Lei 143/2015). Após a receção da comunicação, no prazo máximo de 30 dias a equipa de adoção fornece informação completa relevante para o processo adotivo e para que seja possível formalizar a candidatura (Lei 143/2015). No caso de não serem reunidos os critérios ou requisitos formais basilares para a apresentação da candidatura não é dado início ao processo adotivo (DGSS, 2004).

\subsection{A sessão informativa}

No âmbito dos procedimentos nacionais subjacentes ao processo adotivo, atualmente está planeado reunir os diferentes interessados (i.e., potenciais candidatos à adoção) numa sessão informativa (Sessão A), do Plano de Formação para a Adoção, para a qual os interessados são convocados (ISS, I.P., 2019). Nesta primeira sessão são partilhadas diferentes informa- ções com os interessados, nomeadamente: (a) o conceito de adoção, os objetivos e modalidades; (b) os requisitos e critérios globais que têm de ser cumpridos para que seja possível adotar (e.g., a idade dos candidatos, duração do casamento/união de facto, área de residência); (c) os percursos, caraterísticas e as necessidades específicas das crianças adotáveis; (d) as diferentes etapas do processo de adoção no que se refere à adoção nacional e internacional, e (e) os documentos necessários a entregar para o processo de candidatura (e.g., formulários, documentos formais) (ISS, I.P., 2019). Igualmente, nesta sessão são esclarecidas as dúvidas apresentadas pelos interessados. Independentemente da forma como é realizado o primeiro contacto formal, entre a equipa de adoção da Segurança Social e os interessados em adotar, as informações supra explanadas deverão ser disponibilizadas aos potenciais candidatos à adoção (DGSS, 2004).

\subsection{0 preenchimento dos formulários e a prepa- ração dos documentos necessários}

Após o momento de partilha da informação previamente descrita é proporcionado aos candidatos um intervalo temporal para reflexão. Se o desejo de adotar prevalecer, cabe aos interessados preencher os formulários disponibilizados pela equipa de adoção e reunir toda a documentação necessária (ISS, I.P., 2019) (e.g., fotocópia do cartão de cidadão/passaporte, certidão de casamento/atestado de união de facto, registo criminal especificamente para efeitos de adoção, atestado médico comprovativo do estado de saúde...). Se os interessados em adotar já tiverem filhos também deverão ser entregues documentos adicionais (e.g., fotocópia cartão de cidadão dos filhos) (DGSS, 2004; ISS, I.P., 2014, p. 6).

\subsection{A formalização da candidatura e a receção do certificado de candidatura}

Quando o interessado entregar a sua candidatura e documentos formais solicitados nos serviços de adoção da Segurança Social da área de residência, ou equivalente noutras regiões do país, recebe um certificado de candidatura, formalizando a sua candidatura (ISS, I.P., 2019; Lei 143/2015). 


\subsection{O processo de preparação, avaliação e seleção}

\subsubsection{A avaliação psicossocial do candidato}

A equipa interdisciplinar de adoção, após ter recebido a candidatura, inicia a etapa de estudo e avaliação social e psicológica do candidato que implicará diversos momentos e procedimentos, incluindo entrevistas, uma delas realizada no âmbito de uma visita domiciliária em casa do(s) candidato(s), e a utilização de instrumentos de natureza social e psicológica (ISS, I.P., 2014, 2019). Esta etapa não poderá demorar mais de 6 meses (DGSS, 2004; Lei 143/2015, p. 7243, ver Artigo 44\%). A avaliação social é efetivada por um profissional com formação específica na área do serviço social. No âmbito da avaliação social, que inclui uma entrevista social e uma entrevista domiciliária, é relevante abordar diferentes aspetos, nomeadamente: (a) as motivações do(s) candidato(s) para a adoção; (b) as características da criança que desejam adotar; (c) a adequação da criança desejada às suas circunstâncias pessoais e individuais e à realidade das crianças adotáveis, e (d) aprofundar temáticas e informações constantes nos formulários preenchidos pelos candidatos, após cuidadosa análise dos mesmos (Direção Geral da Segurança Social, 2004). A avaliação psicológica é concretizada por um profissional com formação específica em psicologia e deverá contemplar a exploração mais profunda de uma ampla diversidade de aspetos, nomeadamente: (a) as motivações para a adoção e reações do meio circundante; (b) a composição do sistema familiar alargado, a história da família e a sua dinâmica interna; (c) as características da família nuclear e/ou do casal; (d) a capacidade parental (e.g., experiências educativas, princípios e crenças educativas) e, (e) as expectativas relativas à adoção (e.g., alterações percecionadas como necessárias no funcionamento familiar aquando a integração da criança, o processo de revelação, os receios e ansiedades perante a adoção) (DGSS, 2004). Para além destes momentos de avaliação préestabelecidos uniformemente como obrigatórios pode haver a necessidade de aprofundar ou esclarecer algum aspeto específico que implique mais entrevistas, contactos com profissionais especializados, a medição de alguma característica ou funcionamento específico digno de destaque (Ribeiro \& Teixeira, 2012).

\subsubsection{Participação na segunda ação do plano de formação para a adoção}

Subjacente ao leque de procedimentos preparativos, avaliativos e seletivos no sentido de capacitar "parentalmente" o candidato à adoção e da emissão de um parecer relativo à pretensão do potencial adotante são implementadas sessões formativas (Lei $\mathrm{n}^{\circ}$ 143/2015). É no decurso desta etapa de avaliação psicossocial que o candidato é incitado a participar numa segunda sessão conjunta subjacente ao Plano de Formação para a Adoção (Sessão B) (ISS, I.P., 2014; Lei $n^{0}$ 143/2015). A sessão B tem como objetivos: (a) explorar conjuntamente as motivações para a adoção; (b) partilhar os medos e os mitos sobre a adoção; (c) conhecer as histórias de vida das crianças adotáveis e identificar as suas necessidades; (d) refletir acerca do possível impacto que a história prévia de vida da criança pode ter no adulto; (e) identificar as capacidades adequadas dos adultos capazes de melhor responder às necessidades das crianças, e (f) compreender a relevância da partilha e do trabalho em equipa em todo o processo adotivo (DGSS, 2004).

\subsubsection{O resultado da avaliação psicossocial da candidatura: seleção ou rejeição}

Após finalizada a etapa de avaliação psicossocial, procede-se à análise do processo, em equipa pluridisciplinar, da qual resulta um parecer fundamentado acerca da aceitação ou rejeição da candidatura (DGSS, 2004). No máximo em 6 meses, o candidato terá acesso à apreciação final da avaliação da equipa, sendo-lhe comunicado se a sua candidatura foi selecionada ou rejeitada (ISS, I.P., 2019). Se os profissionais da equipa de adoção apreciarem negativamente a candidatura, antes de tomada a decisão final é comunicada ao candidato a intenção de rejeição da sua candidatura, sendo-lhes concedida a oportunidade para consultar o processo, reunir novos documentos e apresentar uma nova proposta, com novos argumentos e/ou documentos (ISS, I.P., 2019). Se os serviços de adoção aceitarem a nova proposta a candidatura deverá seguir os procedimentos normais seguidamente explanados, terão 10 dias para aceitar a proposta. No caso de o candidato não apresentar uma nova proposta capaz de alterar a intenção de rejeição da candidatura 
será notificado quanto à decisão por parte dos profissionais e a equipa terá de enviar o processo para tribunal no prazo de 15 dias (DGSS, 2004). Adicionalmente, o candidato é igualmente informado acerca do prazo e do tribunal a que se deve dirigir para requerer um recurso da decisão de "não seleção" da sua candidatura (Lei $n^{0} 31 / 2003$; Lei $\left.n^{0} 143 / 2015\right)$, tendo a oportunidade para ser ouvido, através de uma audiência oral ou escrita, e as suas alegações ficarão registadas em ata (DGSS, 2004).

\subsection{Colocação na lista nacional de adoção e o tempo de espera}

Quando a candidatura é selecionada pela equipa de adoção, esta inscreve o candidato na lista nacional de adoção (Lei no 143/2015) iniciando-se aqui o tempo de espera para a apresentação da proposta de uma criança a adotar. $\mathrm{O}$ certificado de seleção do candidato à adoção é válido por 3 anos, sendo potencialmente renovado por período sucessivos idênticos quando solicitado pelo candidato, antes da sua caducidade, e a reapreciação positiva da candidatura (Lei no 143/2015). No decurso desta etapa o candidato poderá ser convocado a participar em algumas sessões de formação cujos objetivos se referem à promoção da qualidade da parentalidade adotiva, instigando o desenvolvimento de conhecimentos e competências úteis para uma melhor integração da criança na família (ISS, I.P., 2019, Lei $\left.n^{0} 143 / 2015\right)$. As sessões fundamentalmente de caráter formativo, constituem a parte $\mathrm{C}$ do Plano de Formação para a Adoção (DGSS, 2004). As ações de formação-preparação dos candidatos têm um caráter obrigatório a nível nacional (Lei $n^{0} 143 / 2015$ ), não obstante alguns centros distritais em Portugal não as conseguirem implementar devido à escassez de técnicos e excesso de trabalho (Almeida, 2019). Paralelamente os profissionais da equipa de adoção analisam e pesquisam as correspondências mais adequadas entre as características e necessidades das crianças a adotar e as características e capacidades dos candidatos recorrendo às duas listas (Lei n ${ }^{\circ} 143 / 2015$ ), a Lista de Crianças e Jovens para a Adoção e a Lista de Candidatos Selecionados para a Adoção Nacional de Residentes em Portugal (e.g., necessidades específicas de saúde, desenvolvimento e educação da criança, compatibilidade entre a origem étnica e religiosa da criança com os valores do candidato, aproximação da criança desejada à criança real, compatibilização entre as características psicológicas da criança e as do candidato) (DGSS, 2004). Os profissionais tentam estabelecer um "matching" entre as "preferências" e características do candidato e as características (Almeida, 2019) e as necessidades da criança, numa perspetiva do "superior interesse da criança". Quando existe mais do que uma correspondência adequada entre uma criança a adotar e um candidato ou um casal de candidatos, a equipa opta pelo(s) candidato(s) que integrou(aram) a lista de candidatos primeiro.

Quando não se encontra um candidato, da lista de candidatos, com o perfil mais adequado para uma determinada criança a adotar, considerando as suas característica e necessidades, os profissionais analisam a Lista de Candidatos à Adoção Internacional Residentes no Estrangeiro. No caso de nesta lista também não ser (em) encontrado(s) candidato(s) com um perfil compatível com o da criança, a criança terá de aguardar que surja um perfil que melhor se adeque (DGSS, 2004).

\subsection{A proposta da criança a adotar}

Quando os profissionais, após a análise, encontram uma correspondência entre as características e necessidades de uma criança a adotar e as de um candidato ou casal de candidatos contactam o(s) candidato(s) para que possa(m) dirigir-se à entidade reguladora onde a equipa de adoção partilha com o(s) candidato(s) alguns dados relevantes do processo da criança a adotar. Após a partilha destas informações, os candidatos possuem um tempo (breve) de reflexão individual/ conjugal, para que a resposta relativa ao interesse em adotar a criança, cujas principais características foram partilhadas, possa ser devidamente ponderada. Após a decisão o(s) candidato(s) informa(m) a equipa.

\subsection{0 período de vinculação: Processo de transição}

Esta etapa caracteriza-se pelos primeiros encontros entre a criança a adotar e o candidato selecionado, que tem $o$ intuito de que ambos se conheçam e se possam aceitar mutuamente (ISS, I.P., 2019), bem como de averiguar a existência de indicadores positivos de percursores significativos para a construção posterior 
de vinculação afetiva entre pais e filhos adotivos (Lei $\left.n^{0} 143 / 2015\right)$. Estes encontros no decurso do período de transição são previamente organizados e observados pelos profissionais da equipa de adoção e da instituição de acolhimento temporário ou que acompanha (m) a criança na família de acolhimento (Lei $\mathrm{n}^{\circ}$ 143/2015) e geralmente acontecem no contexto em que a criança está acolhida, rodeada pelo ambiente que lhe é familiar e com outras crianças e/ou adultos que sejam importantes e significativos para ela. Também podem existir saídas ao exterior devidamente planeadas entre os profissionais e o candidato (Almeida, 2019). Nesta fase são promovidos momentos de reflexão conjunta entre 0 candidato e os profissionais acerca da forma como o processo está a decorrer (Almeida, 2019). Esta etapa de transição deverá ser tão breve quanto possível e embora possa variar, de acordo com as diferentes características das crianças/jovens e potenciais pais adotivos, não deverá ultrapassar os 15 dias (Lei n ${ }^{\circ}$ 143/2015, p. 7244).

Nos casos em que termina esta etapa de conhecimento mútuo e não se verifica uma aceitação de cada uma das partes, a criança e o candidato continuam a integrar as listas de adoção (i.e., a das crianças a adotar e a dos candidatos à adoção), aguardando perfis compatíveis (DGSS, 2004). Quando os primeiros indícios dos processos de vinculação se começam a estabelecer entre pais adotivos e a criança, a equipa de adoção elabora um parecer fundamentado para ser concedida a confiança administrativa da criança. É emitido um certificado de pré-adoção com a confirmação da data em que a criança foi entregue ao adotante. Nesta fase a equipa de adoção informa 0 adotante que tem um prazo de 30 dias para requerer ao Tribunal de Família e Menores da área de residência a curadoria provisória. Paralelamente atualiza-se a Lista de Crianças e Jovens para Adoção colocando relativamente à criança em questão a designação "PréAdoção" (DGSS, 2004).

\subsection{A integração da criança na família adotiva}

\subsubsection{A pré-adoção}

A criança é confiada ao(s) candidato(s), integra a sua família e fica em situação de pré-adoção por um período máximo de 6 meses[1]. Cabe à equipa de adoção acompanhar e avaliar, neste espaço temporal (ISS, I.P., 2019; Lei $n^{0}$ 143/2015), preferencialmente através de observação direta, a integração da criança na família. São considerados alguns indicadores específicos para a avaliação por parte da equipa de profissionais, relativamente às crianças (e.g., surgimento de comportamentos de vinculação; reações de afeto e reveladoras de construção de uma relação de segurança; progressão do desenvolvimento global; adaptação às novas regras e hábitos, apropriação do espaço físico da casa) e relativamente aos pais (e.g., modo como é encarada a adoção; tarefas de rotina familiar para dar resposta às necessidades da criança no domínio da saúde, educação e da socialização; (re)adaptação das rotinas familiares, profissionais, sociais; confronto entre as expectativas prévias e a realidade experienciada; dificuldades e estratégias de resolução; aceitação das características da criança e do seu passado) (DGSS, 2004). Este acompanhamento e avaliação na fase da pré-adoção pode ser gerido diferencialmente por cada equipa de adoção. Algumas equipas de adoção optam por realizar visitas domiciliárias às famílias adotivas, por exemplo em fase pré-adotiva uma semana depois da criança ir para casa da família e, posteriormente, mensalmente.

Nesta fase, $o(\mathrm{~s})$ adotante(s) pode(m) ainda ser convidado(s) a participar em sessões de formação (i.e., Bloco D do Plano de Formação para a Adoção) (ISS, I.P., 2014, 2019). Em qualquer fase desta etapa pode ser cessada a pré-adoção desde que devidamente fundamentada em função do "superior interesse da criança" (Lei no 143/2015, p. 7244). No ano de 2018, a integração familiar de 14 crianças (i.e., 7 meninas e 7 meninos) foi interrompida, nesta ou em fases posteriores (i.e., 6 crianças na fase de transição e 8 no período de pré-adoção), a maioria das crianças (i.e., $78.6 \%$ ) tinha 7 anos ou mais de idade (Conselho Nacional para a Adoção \& Gabinete de Apoio Técnico CNA \& GAT, 2018). As razões subjacentes à interrupção do processo adotivo foram diversas. No perío-

[1] Este intervalo temporal pode ser alargado por mais dois períodos de 3 meses cada, devendo o tribunal ser formalmente informado através da justificação fundamentada relativa à pertinência deste prolongamento (Almeida, 2019). 
do de transição, em que as crianças permaneceram com o(s) candidato(s) à adoção entre 1 e 30 dias, as razões identificadas prendem-se com a ambivalência e dúvidas persistentes, por parte dos candidatos, que dificultam a prossecução do processo, a dificuldade sentida em estabelecer uma relação afetiva que fosse, de acordo com o desejo dos candidatos, semelhante à biológica, incapacidade manifestada para compreender e lidar com o comportamento e os sentimentos de rejeição das crianças, insegurança no papel parental, a dificuldade de adaptação dos candidatos à vida familiar adotiva e a idade da criança ser superior a 10 anos (CNA \& GAT, 2018). As justificações enunciadas nas interrupções no período de pré-adoção, em que as crianças permaneceram com os candidatos adotivos entre 24 dias e 9 meses, foram as dificuldades de vinculação por parte dos candidatos, de ajustamento à dinâmica familiar, descrença na mudança futura, dificuldade em gerir a relação entre $o$ filho adotivo e 0 biológico associada à recusa em aceitar intervenção profissional e em alguns casos, minoritários, de maus tratos físicos e psicológicos dos candidatos à criança (CNA \& GAT, 2018).

Estas situações de término abrupto do processo adotivo são potencialmente devastadoras para as crianças uma vez que a experiência psicoemocional do abandono é reativada e reforçada (Almeida, 2019). A criança ao ser afastada, por razões diversas, da sua família biológica já teve de lidar com o sentimento de perda/abandono e possivelmente até com a autoatribuição de culpa pelo sucedido (Almeida, 2019). Consequentemente é provável que a autoestima, a autoconfiança, a capacidade da criança para acreditar na sua felicidade no seio de uma família e de se empenhar numa relação de vinculação fiquem comprometidas (Almeida, 2019). Nestas situações urge a necessidade de intervenção profissional junto destas crianças.

\subsubsection{0 relatório da pré-adoção, pedido formal da adoção e decisão do Tribunal de Família e Me- nores}

Se os indicadores observados no decurso desta fase de acompanhamento e avaliação forem atingidos de forma expectável e adequada a equipa de adoção redige um relatório que é entregue ao candidato, atra- vés da cópia integral em anexo de um ofício, e informa $o$ candidato que deve ser solicitada a adoção. $\mathrm{O}$ relatório da equipa deverá constar no pedido de adoção que o candidato dirige ao Tribunal de Família e Menores da sua área de residência. Quando for proferida a sentença, o processo formal de adoção é finalizado (ISS, I.P., 2014, 2019). A família adotiva pode ainda, se assim o desejar, solicitar aos serviços acompanhamento pós-adoção (e.g., apoio na resolução de dificuldades subjacentes à parentalidade ou filiação adotivas) (ISS, I.P., 2019).

\section{O processo psicossocial da adoção: a perspeti- va das famílias}

Existem inúmeras semelhanças entre as famílias adotivas e as não adotivas, contudo, existe igualmente um conjunto diversificado de especificidades relativas ao processo adotivo (Brodzinsky, Lang, \& Smith, 1995; Palacios, 2004) e às vivências externas e internas das famílias adotivas, que, em conjunção, com as caraterísticas idiossincráticas de cada um dos implicados e com o que caracteriza as inter-relações familiares e as extra familiares, transformam as suas vivências em verdadeiramente únicas. Os diversos elementos da família adotiva, em cada etapa do ciclo de vida, têm de enfrentar temáticas ou aspetos específicos relacionados com o processo adotivo que interagem $\mathrm{e}$ complexificam a forma como experienciam e como resolvem as tarefas normativas da vida familiar (Brodzinsky et al., 1995).

Entre os diversos aspetos distintivos entre as famílias adotivas e as não adotivas, alguns deles assumem uma especial importância pelas possíveis consequências associadas: (1) A infertilidade e todo o processo pessoal, relacional, médico e social subjacente e que faz parte da realidade de uma elevada percentagem de famílias adotivas; (2) $\mathrm{O}$ processo de tomada de decisão de adoção e as suas implicações internas, relacionais e sociais; (3) A avaliação formal da família adotiva, com o intuito de selecionar apenas os candidatos que reúnem as condições adequadas para uma boa parentalidade e as implicações pessoais e relacionais do processo formal; (4) $\mathrm{O}$ tempo de espera pela criança, como uma "gravidez" abstrata, sem tempo previsto, sem tonturas, enjoos, pontapés, ecografias, 
alterações físicas, emocionais e psicológicas, e sem as amabilidades sociais confirmatórias da sua concretização; (5) A transição para a família adotiva (Brodzinsky et al., 1995) ou a reconfiguração repentina da família aquando a chegada da criança e o desenvolvimento do sentimento de pertença (Palacios, 2004); (6) A perceção de si próprias como famílias semelhantes e/ou diferentes das famílias não adotivas (Palacios, 2004) e a forma como lidam com essa perceção de semelhança versus diferença; (7) As crenças e atitudes relativas ao processo de revelação (Brodzinsky et al., 1995; Palacios, 2004) no decurso da vida familiar (Brodzinsky et al., 1995) e as suas implicações pessoais e relacionais.

Exploramos seguidamente algumas das especificidades do processo psicossocial da adoção, nas suas diferentes etapas, e a forma como podem ser experienciadas pelas famílias adotivas.

\subsection{Motivos e processo de tomada de decisão: 0 início}

Nas "origens" do despoletar da decisão de adotar encontra-se uma etapa de reflexão individual e/ou de casal (Palacios, Sanchez-Sandoval, \& SánchezEspinosa, 1996). A amplitude temporal deste período de reflexão, análise e tomada de decisão pode ser variável em cada situação e pode ser impulsionada por diversos motivos (Palacios et al., 1996). Estes motivos podem ser globalmente agrupados em duas categorias distintas: (a) a adoção tradicional, que diz respeito aos casais que têm dificuldade ou não conseguem conceber um filho biológico e (b) a adoção preferencial, que diz respeito aos casais em que a adoção é uma opção, que não se relaciona com a sua fertilidade (Anderson, Piantanida, \& Andersen, 1993).

Entre os motivos mais frequentes para adotar encontram-se as dificuldades em concretizar a filiação (e.g., infertilidade experienciada entre os casais, pessoas solteiras, divorciadas ou viúvas nas adoções singulares) (Mascarenhas \& Alarcão, 2002). O estudo realizado com 106 famílias adotivas residentes no Distrito de Lisboa revelou que a grande maioria de famílias reportava um problema de infertilidade (Salvaterra, 2007). No mesmo sentido, o estudo realizado em Andaluzia, Espanha, realizado com 393 fa- mílias adotivas de 484 crianças apurou que os motivos mais frequentemente referidos pelos pais, para adotar uma criança foram, para mais de metade das famílias, os problemas de infertilidade, riscos de saúde para a mãe no decurso de uma gravidez ou riscos genéticos para a criança a nascer (Palacios et al., 1996). Reiterando esta tendência também o estudo realizado com famílias adotivas da região do Algarve, revelou que $66 \%$ de famílias adotivas tinham problemas de fertilidade (Almeida, 2017). De facto, a maioria dos candidatos à adoção são casais cuja condição biológica inviabiliza a possibilidade de serem pais (Kirk, 1964, 1981; Mascarenhas \& Alarcão, 2002; Palacios et al., 1996).

A infertilidade [2], de um ou ambos os elementos do casal, poderá ter consequências a nível individual e/ou conjugal, a investigação releva que se pode associar a diversos problemas, nomeadamente a ansiedade, depressão, uma distorção da imagem corporal, baixaautoestima, deterioração na comunicação conjugal, decréscimo da atividade sexual e ressentimento relativamente ao seu parceiro (Shapiro, 1988). Resultados de diversas investigações evidenciam o impacto menos positivo que a infertilidade e os tratamentos de reprodução medicamente assistida podem ter no casal em diferentes domínios (ver Dunkel-Schetter \& Lobel, 1991, Greil, Slauson-Blevins, \& McQuillan, 2010, e Olivius, Friden, Borg, \& Bergh).

Para além da inviabilidade ou elevada dificuldade de uma conceção biológica, os casais inférteis têm de gerir os efeitos psicológicos que, se não forem ade-

[2] A infertilidade constitui o resultado de uma falha a nível orgânico por disfunção do conceto, dos gâmetas ou dos órgãos reprodutores que dificulta ou impossibilita a conceção ou a persecução de uma gravidez. É considerado que um casal é infértil quando não consegue atingir a gravidez no prazo de um ano tendo uma vida sexual contínua, com uma frequência de 3 a 5 vezes por semana de relações sexuais, sem métodos contracetivos e quando a mulher tem menos de 35 anos de idade. Adicionalmente a dificuldade no prosseguimento de uma gravidez, com abortamentos repetitivos (i.e., a partir de 3 consecutivos), é igualmente considerado infertilidade (Associação Portuguesa de Fertilidade - APF, 2020). Considerando a população em idade reprodutiva, estima-se que a infertilidade conjugal se situe entre 15 e $20 \%$, sendo a taxa de infertilidade feminina e masculina equivalente (Associação Portuguesa de Fertilidade - APF, 2020). 
quadamente resolvidos poderão ter um impacto menos positivo no processo adotivo. Kirk (1984) na sua teoria do papel social, concebida com base no seu estudo com 2000 pais adotivos, salientou esta tendência de os pais adotivos levarem a sua angústia e dor da infertilidade para a parentalidade adotiva. Afirmou que quanto mais fragilizado um casal se sinta devido à sua infertilidade mais tendente estará para utilizar como mecanismo de resolução a negação ou a rejeição face à diferença que implica ser uma família não biológica comparativamente às biológicas. Desta forma, parece ser relevante que os pais adotivos, para os quais a infertilidade seja uma realidade, consigam resolver o processo de luto e de aceitação face à infertilidade e impossibilidade ou dificuldade na parentalidade biológica, para que consigam investir, de forma adequada, na criança a adotar (Mascarenhas \& Alarcão, 2002).

De acordo com Rosenberg (1992) existem três importantes momentos subjacentes ao processo de decisão que já foram vivenciados por muitos dos candidatos à adoção no momento em que tomam a iniciativa de adotar: (1) Constatar e aceitar a dificuldade ou incapacidade para conceber um filho biológico; (2) Aceitar assumir um papel parental de uma criança com a qual não existe um vínculo biológico, e (3) Definir as principais características da criança que se pretende adotar.

Em relação ao início do processo formal da adoção, os candidatos experienciam diversas incertezas e fontes de stress. Uma das incertezas relaciona-se com 0 tempo de espera (que em Portugal varia de acordo com diversos fatores e é inversamente proporcional à idade da criança indicada como limite máximo desejado pelos candidatos) (Mascarenhas \& Alarcão, 2002). Outro fator de stress para os futuros pais adotivos, nesta fase, é a incerteza de conseguirem, ou não, corresponder às exigências formais de seleção para a adoção (Palacios, 2004). Outro dos aspetos é a necessidade de transmitirem a sua decisão à família e meio envolvente, muitas vezes com a devida justificação, que poderá reativar e intensificar as problemáticas internas relativas à infertilidade e os sentimentos de diferença comparativamente às famílias biológicas no seu processo paulatino e óbvio de gravidez (Mascarenhas \& Alarcão, 2002).

\subsection{O tempo de espera: Gravidez por tempo indeterminado}

Em Portugal, entre a fase formal em que os candidatos são selecionados e da sua colocação na lista nacional de adoção e a proposta da criança a adotar existe um importante hiato temporal comumente designado como o tempo de espera. O tempo de espera depende de diversos fatores, nomeadamente as características das crianças definidas como desejáveis pelos candidatos; o número de crianças adotáveis com essas características, o número de candidatos em lista de espera para adotar (ISS, I.P., 2019) e a correspondência entre as necessidades específicas das crianças a adotar e $o$ perfil dos candidatos. O tempo de espera parece ter aumentado de forma acentuada nos últimos anos. $\mathrm{O}$ estudo realizado com famílias adotivas que adotaram na região do Algarve antes do ano de 2013 revelaram uma média de tempo de espera de 2 anos e 3 meses (Almeida, 2017). De acordo com uma análise aproximada, considerando os números divulgados no relatório elaborado pelo Conselho Nacional para a Adoção - CNA (ver CNA, 2017 e CNA \& GAT, 2018), os candidatos à adoção que adotaram no ano de 2017 esperaram em média cerca de 4 anos e meio, embora com uma ampla variedade de tempo de espera entre os candidatos que variou entre menos de 1 ano para $8.6 \%$ dos candidatos e 9 anos para $0.9 \%$ dos candidatos, sendo que a maior percentagem de candidatos (i.e., 32\%) esperou cerca de 5 anos. A análise geral dos números fornecidos no relatório relativo ao ano de 2018 permite constatar uma média aproximada de 4 anos e 7 meses de tempo de espera, sendo que a maior percentagem de pais adotivos (i.e., 35.1\%) esperou 6 anos pelo seu filho adotivo. A variabilidade também é muito evidente uma vez que o tempo de espera dos candidatos que adotaram em 2018 variou entre menos de 1 ano (i.e., $4.7 \%$ dos candidatos) e 12 anos (i.e., cerca de $2 \%$ dos candidatos) (ver CNA \& GAT, 2018). As razões justificativas para esta tendência são variadas. $\mathrm{O}$ número decrescente de crianças com sentenças de adotabilidade decretadas por parte dos tribunais (e.g., em 2016 - 361 crianças com sentenças decretadas, em 2017 - 284 crianças e em 2018 -183 crianças, num ano observou-se um decréscimo de $36 \%$ ) e o facto de o número de candidaturas à ado- 
ção ser sete vezes superior ao número de crianças em situação de adotabilidade (CNA \& GAT, 2018) são as principais razões indicadas. Adicionalmente a discrepância significativa entre o perfil desejável relativo às características da criança a adotar indicado pelo(s) candidato(s) à adoção na sua candidatura e as características das crianças disponíveis para adoção é outra das razões de destaque (CNA \& GAT, 2018). Em 2018 foi possível observar que $71 \%$ das candidaturas referem crianças até aos 3 anos de idade, no entanto a realidade é que as crianças disponíveis para a adoção com menos de 3 anos são menos de $20 \%$. As pretensões dos candidatos para adotar crianças com 7 anos ou mais são menos de $5 \%$ enquanto que os dados revelam que $65 \%$ das crianças para adotar enquadramse nessa faixa etária a partir dos 7 anos de idade (CNA \& GAT, 2018). O aumento do número de crianças mais velhas e com problemas de saúde para adotar tem sido evidente (CNA \& GAT, 2018), o que não é espelhado no perfil desejado pelos candidatos. Como é evidente perante estes dados quanto mais restritivo for o perfil de características da criança a adotar maior será o tempo de espera por parte dos candidatos à adoção.

Estes dados revelam que o tempo de espera dos candidatos é grande e, em geral, muito diferente da situação de uma "gravidez biológica". O tempo de cspcra dos candidatos à adoção é vivido como um período de indefinição e imprevisibilidade, uma vez que os futuros pais adotivos conseguem delimitar o seu início, mas não fazem a mínima ideia como delimitar a sua conclusão. Ao contrário do que é experienciado numa gravidez biológica, no decurso desta "gravidez" abstrata, apenas "psicológica", os futuros pais não têm conhecimento acerca de uma previsão de uma data aproximada para o "nascimento" do seu filho (Brodzinsky et al., 1995; Salvaterra \& Veríssimo, 2008). Desta forma, os futuros pais adotivos tendem a experienciar nesta fase, incertezas, vazios internos, ansiedade, angustia, insegurança, intranquilidade, nervosismo e stress (Berástegui, 2008; Ferreira, Pires, \& Salvaterra, 2004; Mascarenhas \& Alarcão, 2002; Salvaterra \& Veríssimo, 2008; Sandelowski, Harris, \& Holditch-Davis, 2007). Os sentimentos de ansiedade (Brodzinsky et al., 1998; Salvaterra, 2007), desampa- ro e frequentemente depressão podem mesmo levar os candidatos a questionarem-se acerca do seu direito para serem pais (Brodzinsky et al., 1998) como acontece naturalmente com a grande maioria das pessoas que os rodeiam. Não obstante as tendências menos positivas, alguns candidatos relatam um relacionamento conjugal intacto e uma comunicação em casal de boa qualidade no decurso do tempo de espera (Almeida, 2017; Salvaterra, 2007).

Face a este panorama global, os candidatos acabam por recorrer a uma diversidade de estratégias para que consigam ultrapassar esta etapa, caracterizada por algumas dificuldades, de uma forma mais saudável. Alguns dos adotantes optam por ir contactando regularmente com a equipa de adoção, no sentido de se certificarem que não foram esquecidos e na indagação de novidades, outros dedicam-se mais a outras dimensões da vida, como à profissional. Não obstante as especificidades de cada indivíduo, a maioria dos futuros pais adotivos opta por um investimento na sua rede de suporte social informal, procurando o apoio das pessoas mais significativas para si, como dos familiares e amigos, ou mesmo aproximando-se das crianças que integram a sua rede familiar e/ou social (Berástegui, 2008; Ferreira et al., 2004).

Independentemente das características de cada candidato c das cstratćgias que adotam nesta ctapa ć rclcvante que esta fase seja aproveitada para os futuros pais conseguirem internalizar, nas suas estruturas mentais, a parentalidade, ou seja, o seu novo papel de pais (Sandelowski et al., 2007). Provavelmente esta tarefa de progressivamente se "parentalizarem" é mais difícil de ser concretizada comparativamente aos pais biológicos devido a toda a abstração que reveste esta fase, em que não existe qualquer pista confirmatória da sua concretização (e.g., o tempo de espera sem delimitação, ausência de sintomas físicos, ausência de qualquer tipo de interação com o filho a "fazerse pessoa", falta de informações concretas de obstetras, ausência de olhares e comentários sociais reforçadores do estado de parentalidade iminente).

Este período de espera, devido à necessidade de "conteúdo" concreto por parte dos candidatos, pode ser aproveitado para ser experienciado como uma "espera ativa", ou seja com investimento parental em 
alguns aspetos particulares, nomeadamente no ajustamento de expetativas relativas à criança adotada e às experiências adotivas futuras, na antecipação de tarefas e dificuldades que possam emergir futuramente na integração da criança adotada e, ainda, no desenvolvimento progressivo de um reportório de estratégias adequadas para melhor enfrentar ou resolver estas dificuldades (Angulo \& Reguilón, 2001). Neste sentido, a equipa de adoção poderá ter um papel fundamental para informar, apoiar e incentivar o aumento de conhecimentos e de competências no âmbito da parentalidade adotiva.

\subsection{A chegada da criança, a sua adaptação e de- senvolvimento na família adotiva: lua-de-mel, apropriação e sentido de pertença}

Em Portugal, a fase da chegada da criança à família ocorre rapidamente. Desde que a família e a criança se conhecem até a criança ir para casa da família adotiva, no caso de existir uma boa qualidade nas interações diádicas observadas entre o(s) adotante(s) e a criança, geralmente decorrem apenas alguns dias.

De acordo com a perceção parental de algumas famílias adotivas, na região de Lisboa, esta primeira fase de transição tende a ser muito repentina, embora tal não seja perspetivado pelos pais adotivos como algo menos positivo, considerando que os procedimentos subjacentes à entrega da criança foram maioritariamente adequados ou muito adequados (Salvaterra, 2007).

Nesta fase de transição para a parentalidade as grandes tarefas desenvolvimentais normativas, ou objetivos que se colocam no ciclo de vida familiar, para as famílias adotivas são semelhantes às colocadas para as famílias não adotivas, incluindo a criação de um modelo de parentalidade (Mascarenhas \& Alarcão, 2002) e o estabelecimento do vínculo afetivo pais-criança (Alarcão, 2000). A transição para a parentalidade geralmente envolve alterações consideráveis no sistema familiar, na medida em que o aumento da fadiga parental implica frequentemente transformações específicas em diversas dimensões da vida do casal (Brodzinsky et al., 1995). Resultados de investigação indicam um decréscimo de acontecimentos relacionais positivos e de tempo de lazer focado na relação conjugal (e.g., MacDermid, Huston,
\& McHale, 1990), de socialização (Simpson, Rholes, Campbell, Tran, \& Wilson, 2003), e um aumento considerável de conflito conjugal (Cowan \& Cowan, 2000). De facto, a literatura científica tende a concluir que a transição para a parentalidade constitui um período stressante para os novos pais (Cowan \& Cowan, 1995), que implica alguma deterioração na relação conjugal (Doss, Rhoades, Stanley, \& Markman, 2009). Esta deterioração tende a ser súbita após o nascimento do primeiro filho e a persistir pelo menos nos 4 primeiros anos após o nascimento do filho (Doss et al., 2009).

As famílias adotivas para além das tarefas normativas associadas à transição para a parentalidade, comuns a todas as famílias aquando a chegada de um filho, têm algumas tarefas e circunstâncias que lhes são particulares (Palacios, 2004). As circunstâncias e características que envolvem a chegada da criança, a fase da Préadoção (que como vimos tem a duração formal de 6 meses) é outra das especificidades das famílias adotivas. A investigação indica que esta é uma etapa experienciada pelos pais como difícil. Num estudo realizado em Portugal, com famílias adotivas de Lisboa, as famílias referem a fase da pré-adoção como uma das vividas com mais dificuldade (Salvaterra, 2007). No mesmo sentido, um estudo realizado no Distrito do Porto, quase metade das famílias adotivas inquiridas refere a vivência difícil nesta etapa (Santos et al., 2000). Em Espanha, num estudo realizado com famílias adotivas provenientes de Andaluzia, as famílias referem que o período de pré-adoção é geralmente vivido com alguma preocupação e insegurança. Metade das famílias Andaluzas inquiridas considerou o processo de préadoção como complicado (Palacios, 2004).

Uma outra fase muito específica das famílias adotivas, na transição para a parentalidade, é a fase da decisão judicial, que é outra das relatadas pelas famílias adotivas como sendo das mais difíceis de ser vividas (Salvaterra, 2007). O tempo até ser decretada a adoção formal da criança por via judicial é vivido, por algumas famílias, como um período que teve pouco impacto, embora outras famílias refiram um impacto negativo nas suas vidas, com receios de que o "filho" recém-chegado pudesse ser reclamado pelos pais biológicos (Salvaterra, 2007). 
Não obstante estas angústias vividas pelos pais adotivos, a propósito das formalidades associadas ao processo adotivo, os primeiros tempos vividos após a chegada da criança, geralmente caraterizam-se como uma lua-de-mel (Brodzinsky et al., 1998; Mascarenhas \& Alarcão, 2002; Palacios, 2004). A fase da luade-mel faz parte do período inicial da chegada e integração da criança adotiva na família, caracterizada por uma fase de "enamoramento" entre pais e filho, em que tudo corre bem (Mascarenhas \& Alarcão, 2002; Palacios, 2004). Geralmente esta "doce" e tranquila fase antecede outras de maiores desafios para os pais adotivos (Brodzinsky et al., 1998).

Após esta fase de deslumbramento afetivo inicial, por vezes, começam a surgir alguns problemas, que acontecem principalmente com crianças adotadas com mais idade. Estes problemas tendem a relacionar-se sobretudo com as experiências pré-adotivas das crianças e com o seu medo do abandono que podem levar a que sintam a necessidade de confirmar a incondicionalidade do amor dos pais e a certeza de que não serão novamente abandonadas, provocando e desafiando os pais no sentido de testarem o amor deles (Mascarenhas \& Alarcão, 2002). Perante estes comportamentos desafiadores os pais adotivos questionam se os comportamentos exibidos são comportamentos inadequados típicos de qualquer criança, devendo ser encarados como tal, ou se serão provocados por todas as experiências passadas adversas que a criança viveu e que, por isso, devem reagir de forma diferente (Archer, 1999). Estas e outras questões podem traduzir-se em dificuldades educativas exibidas pelos pais adotivos, relacionadas com o uso da autoridade parental por compaixão pelo sofrimento passado da criança ou/e por recearem perder 0 afeto da criança, levandoos a exibirem um estilo educativo parental permissivo ou ambivalente (Mascarenhas \& Alarcão, 2002). Adicionalmente aos comportamentos desafiadores, as crianças adotadas podem manifestar problemas de sono, alimentares ou de controlo dos esfíncteres. Estes comportamentos podem promover a insegurança dos pais e interpretá-los como uma inadaptação à família adotiva ou a problemas genéticos da criança. Não obstante, estes comportamentos frequentemente serem adaptativos, o seu surgimento poderá fazer emer- gir obstáculos ao processo de filiação e de construção da parentalidade, sustentando a clivagem entre a herança biológica e a influência possível do meio ambiente (Mascarenhas \& Alarcão, 2002).

As crianças adotadas podem trazer consigo uma dura história e uma diversidade de experiências adversas (Rosenthal, 1993). Estas crianças têm uma maior probabilidade de terem sido fruto de gravidezes com stress e sem acompanhamento médico, de partos e pós -partos associados a complicações diversas (Bohman, 1970; Hoopes, 1982) e de provirem de famílias biológicas com problemas psicológicos (Cadoret, 1990; Loehlin, Willerman, \& Horn, 1982). É relevante não descurar o potencial impacto dessas experiências adversas em fases precoces da vida destas crianças no seu comportamento e desenvolvimento emocional (Archer, 1999). A bagagem de experiências menos positivas da criança pode dificultar as relações entre pais e filho, o funcionamento familiar, e, consequentemente o ajustamento da criança na família adotiva (Rosenthal, 1993).

De facto, a integração da criança numa família adotiva não apaga as experiências do passado da criança e as suas estratégias de sobrevivência aprendidas na adversidade (Archer, 1999), não obstante a possibilidade de "reescrever" o presente e o seu futuro. Adicionalmente a estas dificuldades acrescidas nas famílias adotivas são frequentes as interrogações e questões dos pais no que se refere ao problema de infertilidade e à filiação psicológica, bem como a dúvidas relativas ao património hereditário que acompanha a criança e suas potenciais implicações no seu desenvolvimento e no funcionamento familiar (Alarcão, 2000). Estas questões podem incrementar a discrepância entre a criança imaginária e a criança real cujo impacto nas relações entre pais e filhos pode ser relevante (Isabella \& Belsky, 1991). Desta forma, é possível compreender que para além do stress normativo comum a qualquer família na transição para a parentalidade, as famílias adotivas estão sujeitas a fontes de stress adicionais associadas ao processo adotivo (Alarcão, 2000).

Por toda a acumulação de dificuldades possíveis nas experiências familiares adotivas as redes de suporte social formal (i.e., os profissionais e serviços) e de supor- 
te social informal (a família e os amigos) podem ter um papel muito relevantes, para que estes pais possam partilhar as suas dificuldades e sentimentos a eles associados e, com mais segurança, redefinir os comportamentos mais adequados (Alarcão, 2000). Neste sentido, os pais adotivos do estudo realizado em Espanha, referem que perante os problemas encontrados utilizam recursos diversificados, nomeadamente apoio conjugal, de amigos e familiares e apoio profissional (Palacios, 2004).

Apesar das fontes de stress adicionais experienciadas na transição para a parentalidade nas famílias adotivas, existem algumas singularidades que se podem assumir como aspetos positivos para a família (Brodzinsky et al., 1995; Palacios, 2004), podendo constituir-se como importantes facilitadores para superar dificuldades com mais facilidade comparativamente com os pais não adotivos (Brodzinsky, 1998). O facto da idade média da transição para a parentalidade adotiva ser superior à idade dos pais não adotivos, geralmente encontra-se associado a mais anos de relação conjugal, a uma maior estabilidade profissional, maior segurança financeira e a uma maior capacidade para enfrentar as dificuldades subjacentes à parentalidade e à vida familiar globalmente considerada (Brodzinsky et al., 1995; Brodzinsky, et al., 1998).

$\mathrm{O}$ facto de as famílias adotivas terem sido formalmente avaliadas e selecionadas, por parte de uma equipa de profissionais qualificados conhecedores das dificuldades subjacentes ao processo adotivo, também poderá funcionar como outro aspeto positivo destas famílias (Palacios, 2004). Para muitas famílias adotivas, também o longo percurso de dificuldades e sofrimento decorrentes da infertilidade poderá (quando os processos de "luto e aceitação" são adequadamente resolvidos) predispor o casal para um forte desejo e preenchimento aquando a integração da criança, podendo funcionar como efeito protetor das dificuldades possíveis (Brodzinsky et al., 1995). No mesmo sentido, também as expectativas positivas dos pais adotivos em relação ao efeito positivo que ter um filho terá na sua vida pessoal e familiar (Brodzinsky, et al.,1998) podem assumir-se como um importante fator de proteção nestas famílias.

Considerando esta importante fase de integração e adaptação da criança e da família adotiva, é relatada uma perceção de pais adotivos portugueses, residentes nas zonas de Lisboa ou do Algarve, bastante positiva. A maioria dos pais inquiridos refere sentir-se muito satisfeita com as caraterísticas atuais dos filhos e que a sua vida familiar é mais feliz ou muito mais feliz após a adoção. Os pais adotivos referem ainda que os filhos tendem a progredir de forma bastante positiva a diversos níveis (e.g., saúde, crescimento psicológico e nas relações com a família adotiva), mesmo quando inicialmente apresentavam algumas dificuldades de saúde, desenvolvimento, comportamento, alimentação e/ou sono. Estes pais tendem a considerar que as maiores influências no desenvolvimento dos filhos são as experiências na família adotiva e a desvalorizar as ex-periências e influências ambientais e genéticas/ biológicas da vida passada, pré-adotiva dos seus filhos (Almeida, 2017; Salvaterra, 2007). De facto, os resultados de investigação e a experiência clínica de diversos profissionais salientam que esta fase da vida familiar adotiva, em geral, tende a ser bastante bemsucedida (Brodzinsky \& Huffman, 1988).

Em suma, não obstante o relato maioritário de "finais felizes e muito felizes" nos processos adotivos existe ainda o "reverso da medalha", situações muito preocupantes de inadequação ou de ausência ou parca adequação e/ou ajustamento familiar na adoção cuja situação limite são os casos de interrupção do processo adotivo. Adicionalmente existem inúmeros aspetos a melhorar no âmbito destes processos considerando múltiplas dimensões, nomeadamente a sensibilização e formação dos profissionais envolvidos, a proficiência dos processos formais, a excelência na avaliação e preparação dos candidatos e na preparação das crianças, o acompanhamento, apoio e intervenção com mestria junto das famílias por adoção. Faz então todo o sentido que continuemos a refletir, a investigar e a escrever sobre a adoção!

* Este artigo integra um trabalho financiado pela Fundação para a Ciência e Tecnologia — FCT (SFRH/ BD/64040/2009) e foi parcialmente financiado por fundos nacionais através da FCT - Fundação para a Ciência e a Tecnologia, I.P., no âm-bito do projeto CIP - Ref UIDB/PSI/04345/2020. 


\section{Referências}

Alarcão, M. (2000). (Des)Equilíbrios familiares: Uma visão sistémica. Coimbra: Quarteto Editora.

Almeida, A. S. (2017). O processo adotivo: caracteristicas psicossociais, disponibilidade emocional parental e desenvolvimento das crianças. Tese de doutoramento não publicada, Faculdade de Ciências Humanas e Sociais da Universidade do Algarve, Portugal.

Almeida, M. J. R. (2019). O processo de adoção em Portugal no século XXI. Tese de mestrado não publicada, Instituto Universitário de Lisboa ISCTE IUL, Portugal.

Anderson, S., Piantanida, M., \& Anderson, C. (1993). Normal family processes in adoptive families. In F. Walsh (Ed.). Normal family processes (2nd ed.) (pp. 254-281). New York: Guilford Press.

Angulo, J., \& Reguilón, J. (2001). Hijos del corazón. Guía útil para padres adoptivos. Madrid: Ediciones Temas de Hoy.

Archer, J. (1999). The Nature of Grief; The Evolution and Psychology of Reactions to Loss. New York: Routledge.

Associação Portuguesa de Fertilidade (2020). Infertilidade. Retirado a 26 de setembro de 2020 de http:// www.apfertilidade.org/infertilidade.php

Berástegui, A. (2008). El tiempo de la espera en la adopción internacional: vivencia de la espera y estrategias de afrontamiento. Psicothema, 20(4), 551-556.

Bohman, M. (1970). Adopted Children and Their Families: A Follow-up Study of Adopted Children, Their Background, Environment and Adjustment. Stockholm: Proprius.

Brodzinsky, D. M. \& Huffman, L. (1988). Transition to adoptive parenthood. Marriage and Family Review, 6, 267-286.

Brodzinsky, D. M., Lang, R., \& Smith, D. W. (1995). Parenting adopted children. In M. H. Bornstein (Ed.), Handbook of parenting (pp. 209-232). Mahwah, NJ: Lawrence Erlbaum.

Brodzinsky, D. M., Smith, D. W., \& Brodzinsky, A. B. (1998). Children's adjustment to adoption: Developmental and clinical issues. California: Sage Publications.

Cadoret, R. J. (1990). Biologic perspectives of adoptee adjustment. In D. Brodzinsky \& M. Schechter (Eds.), The Psychology of adoption. (pp. 25-41). New-York: Oxford University Press.

Conselho Nacional para a Adoção \& Gabinete de Apoio Técnico - CNA \& GAT (2018). Relatório Anual de Atividades 2018. Conselho Nacional para a Adoção.

Conselho Nacional para a Adoção (2017). Relatório Anual de Atividades 2017. Conselho Nacional para a Adoção.

Cowan, C. P., \& Cowan, P.A. (1995). Interventions to ease the transition to parenthood: Why they are needed and what they can do. Family Relations: Journal of Applied Family \& Child Studies, 44, 412-423.

Cowan, C. P., \& Cowan, P.A. (2000). When partners become parents: The big life change for couples. Mahwah, New Jersey: Lawrence Erlbaum Associates.

Decreto-Lei no ${ }^{0}$ 4344. Ministério da Justiça. Diário do Governo nº 274/1966, Série I de 1966, 1883-2086.

Direção Geral da Segurança Social - DGSS (2004). Adoção: Manual de Procedimentos. Lisboa: Direção Geral da Segurança Social.

Doss, B. D., Rhoades, G. K., Stanley, S. M., \& Markman. H. J. (2009). The Effect of the Transition to Parenthood on Relationship Quality: An Eight-Year Prospective Study. Journal of Personality and Social Psychology, 96(3), 601-619. doi:10.1037/a0013969. 
Dunkel-Schetter, C., \& Lobel, M. (1991). Psychological Reactions to Infertility. In A. 1. Stanton, c. DunkelSchetter (Eds), Infertility. (pp. 29-57). Retirado a 28 de setembro de 2020 de https://link.springer.com/ chapter/10.1007/978-1-4899-0753-0_3

Epifânio, R. M., \& Farinha, A. H. (1987). Organização Tutelar de Menores. Contributo para uma visão interdisciplinar do Direito de Menores e da Familia. Coimbra: Livraria Almedina.

Ferreira, S. A., Pires, A., \& Salvaterra, F. (2004). Filho do coração... adopção e comportamento parental. Análise Psicológica, 2(XXII), 399-411.

Goiri, P., \& Latorre, F. (2010). Adotar: perspetivas y enfoques históricos (un análisis desde los derechos humanos). In F. Latorre (Ed.), Adopción hoy: nuevos desafios, nuevas estrategias (pp. 41-72). Bilbao: Ediciones Mensajero.

Greil, A. L., Slauson-Blevins, K., \& McQuillan, J. (2010). The experience of infertility: a review of recent literature. Sociol Health Illn, 32, 140-162.

Hoopes, J. L. (1982). Prediction in child development: A longitudinal study of adoptive and nonadoptive families. New York: Child Welfare League of America.

Instituto da Segurança Social, I.P. (2014). Guia Prático - Adoção. Instituto da Segurança Social, I.P.

Instituto da Segurança Social, I.P. (2019). Guia Prático - Adoção. Instituto da Segurança Social, I.P.

Isabella, R. A. \& Belsky, J. (1991). Interactional synchrony and the origins of mother-infant attachment: A replication study. Child Development, 62, 373-384.

Kirk, H. D. (1984, Rev. ed.). Shared Fate. WA: Ben-Simon.

Lei 31/2003. Altera o Código Civil, a Lei de Protecção de Crianças e Jovens em Perigo, o Decreto-Lei $n^{\circ}$ 185/93, de 22 de maio, a Organização Tutelar de Menores e o Regime Jurídico da Adopção. Diário da República - I Série A, $\mathrm{N}^{\circ} 193$ - 22 de agosto de 2003, 5313-5329.

Lei 143/2015. Altera o Código Civil, aprovado pelo Decreto-Lei $n^{\circ} 47$ 344, de 25 de novembro de 1966, e o Código de Registo Civil, aprovado pelo Decreto-Lei $n^{\circ} 131 / 95$, de 6 de junho, e aprova o regime Jurídico do Processo de Adoção. Diário da República - $1^{\text {a }}$ Série - No 175 - 8 de setembro de 2015, 7232-7251.

Loehlin, J. C., Willerman, L., \& Horn, J. M. (1982). Personality resemblances between unwed mothers and their adopted away offspring. Journal of Personality and Social Psychology, 42, 1089-1099.

MacDermid, S. M., Huston, T. L., \& McHale, S. M. (1990). Changes in marriage associated with the transition to parenthood: Individual differences as a function of sex-role attitudes and changes in the division of household labor. Journal of Marriage and the Family, 52, 475-486.

Mascarenhas, M. C., \& Alarcão, M. (2002). Famílias adoptivas e processo de adopção, in C. Machado \& R. A. Gonçalves (org.), Violência e vítimas de crimes. Vol. 2: Crianças. (pp. 245-289). Coimbra: Quarteto Editora.

Olivius, C., Friden, B., Borg, G., \& Bergh, C. (2004). Why do couples discontinue in vitro fertilization treatment? A cohort study. Fertil Steril, 81, 258-261.

Palacios, J. (2004, 5 ad.). Famílias Adoptivas. In M. J. Rodrigo \& J. Palácios (Coords.). Familia y desarrollo humano. Psicologia y Educación (pp. 353-371). Madrid: Alianza Editorial.

Palacios, J., Sanchez-Sandoval, Y., \& Sánchez-Espinosa, E. (1996). La adoptión en Andalucía. Sevilla: Junta de Andalucía. Consejería de Asuntos Sociales. Dirección General de Atención al Niño.

Ribeiro, C., \& Teixeira, C. (2012). Sonhos trazidos no bico de uma cegonha. Falando sobre a adoção em Portugal. Vila Nova de Gaia: Diego Martínez Lora, Editor.

Rosenberg, E. B. (1992). The adoption life cycle: the children and their families through the year. New York: Free Press. 
Rosenthal, J. A. (1993). Outcomes of adoption of children with special needs. The Future of Children: Adoption, $3(1), 77-88$.

Salvaterra, F., \& Veríssimo, M. (2008). A adoção: o direito e os afectos. Caracterização das famílias adoptivas do distrito de Lisboa. Análise Psicológica, 3(XXVI), 501-517.

Salvaterra, M. F. (2007). Vinculação e Adoção (Tese de Dissertação de Doutoramento). Acedido em http:// repositorio.ispa.pt/bitstream/10400.12/75/1/TES\%20SALV1.pdf

Sandelowski, M., Harris, B., \& Holditch-Davis, D. (2007). Somewhere out there. Parental Claiming in the preadoption waiting period. Journal of contemporary ethnography, 24(4), 464-486.

Santos, R. M. et al. (2000). Outros filhos, os mesmos direitos: Estudo sobre a problemática da adopção no Distrito do Porto de 1988 a 1997 - Projecto de investigação no âmbito do programa "Ser criança". Porto: Gráfica Maiadouro.

Shapiro, C. H. (1988). Infertility and pregnancy loss: A guide for helping professionals. San Francisco: Jossey-Bass.

Simpson, J. A., Rholes, W. S., Campbell, L., Tran, S., \& Wilson, C. L. (2003). Adult attachment, the transition to parenthood, and depressive symptoms. Journal of Personality and Social Psychology, 84, 1172-1187.

Weckler, J.E. (1953). Adoption on Mokil. American Anthropologist, 55(4), 555-568. 